\title{
Renal Handling of Aluminium
}

\author{
D.G. Shirley ${ }^{\mathrm{a}}$ C.J. Lote ${ }^{\mathrm{b}}$ \\ ${ }^{a}$ Department of Physiology and Centre for Nephrology, University College London, London, and \\ ${ }^{b}$ Division of Medical Sciences, University of Birmingham, Birmingham, UK
}

\section{Key Words}

Aluminium excretion - Aluminium filterability •

Aluminium reabsorption - Citrate $\cdot$ Micropuncture

\begin{abstract}
Aluminium (Al) is absorbed from a variety of foodstuffs and medications. Its major route of elimination from the body is in the urine. However, current knowledge concerning its glomerular filtration and, more particularly, its reabsorption/secretion is fragmentary. Most (80-90\%) of $\mathrm{Al}$ in the plasma is normally bound to protein (mainly transferrin) and is therefore unfilterable; the remainder is bound to low molecular mass compounds, of which citrate appears to be the most important. In vitro determinations using artificial membranes indicate that $\sim 10 \%$ of $\mathrm{Al}$ is filtered at normal plasma concentrations. However, when plasma $\mathrm{Al}$ is raised experimentally, its filterability falls, unless the excess Al is complexed with citrate; the aluminium citrate complex appears to be freely filtered. Information on tubular Al reabsorption at normal plasma concentrations is inconsistent. Filtered Al appears to be at least partially reabsorbed, although the reabsorptive mechanisms remain speculative. A consensus is emerging that elevated plasma Al concentrations result in a fall in fractional $\mathrm{Al}$ reabsorption, and a recent micropuncture study indicates that under these circumstances the only significant site of Al reabsorption is the loop of Henle.
\end{abstract}

Copyright $\subset 2005$ S. Karger AG, Basel

\section{Introduction}

Aluminium (Al), the most abundant metal in the Earth's crust, is present in a variety of foodstuffs (e.g. tea, self-raising flour) and medications (e.g. vaccines, antacids, phosphate binders) as well as in domestic water supplies. Although only a small fraction (normally $\sim 0.2 \%$ ) of ingested $\mathrm{Al}$ is absorbed into the blood [1], it is vital that absorbed $\mathrm{Al}$ is quickly removed from the body because $\mathrm{Al}$ accumulation is a risk factor in a number of disorders including microcytic anaemia, osteomalacia and dementia [2]. A small amount of $\mathrm{Al}$ is excreted in bile, but the major route of $\mathrm{Al}$ elimination is by the kidneys. Unsurprisingly, therefore, patients with renal insufficiency are more susceptible to Al toxicity [3]. Moreover, such patients often receive Al-based, phosphate-binding gels to control their serum phosphate, thereby exacerbating the problem. In addition, until the situation was recognised and largely rectified, many dialysis patients were exposed to increased risk owing to the high Al content of some dialysis fluids.

Given the key role of the kidneys in preventing harmful $\mathrm{Al}$ accumulation under normal circumstances, it is clear that strategies for dealing with cases of accidental exposure to high Al levels (as in the 'Camelford incident' in Cornwall, UK, in 1988, when aluminium sulphate was added to drinking water) need to focus on enhancing its renal elimination. Such strategies must rely on knowledge of the renal handling of $\mathrm{Al}$ (glomerular filtration, tubular reabsorption/secretion) and the factors that can affect these processes. Current knowledge is surprisingly fragmentary. In this minireview, we will attempt to piece together the available information on renal $\mathrm{Al}$ handling, at both physiological and pathological plasma concentrations.

\section{KARGER \\ Fax +4161306 1234 E-Mail karger@karger.ch} www.karger.com
Dr. D.G. Shirley

Department of Physiology and Centre for Nephrology

University College London, Hampstead Campus

Rowland Hill Street, London NW3 2PF (UK)

Tel. +44 207472 6499, Fax +44 207472 6476, E-Mail david.shirley@ucl.ac.uk 


\section{Glomerular Filtration}

\section{Physiological Concentrations}

A typical value for total body $\mathrm{Al}$ in a healthy subject is $\sim 30 \mathrm{mg}$. A wide range of values has been reported for normal plasma $\mathrm{Al}$ concentration [see 4], probably because some early measurements were subject to contamination; more recent studies indicate a figure in the range $2-5 \mu \mathrm{g} / 1$. Practically all $\mathrm{Al}$ in plasma exists as complexes, either with high molecular mass (HMM) or low molecular mass (LMM) compounds. As discussed in detail by van Landeghem et al. [4], attempts to quantify the various binding ligands have provided vastly differing results, depending on the methodologies used. A reasonable consensus is that $80-90 \%$ of $\mathrm{Al}$ is bound to protein, largely transferrin, whilst the remainder is bound to LMM compounds. The LMM anions in plasma that could potentially bind $\mathrm{Al}$ are citrate, phosphate, hydroxide and silicate. Of these, citrate is thought to be the principal, perhaps virtually exclusive, binder under normal circumstances $[1,4,5]$.

It is reasonable to assume that $\mathrm{Al}$ bound to LMM compounds will be filtered at the glomerulus, whilst $\mathrm{Al}$ bound to HMM compounds will not. Direct assessment of glomerular filterability of $\mathrm{Al}$ in humans is obviously impossible, but indirect determinations have been made using artificial filtration membranes. Methodological errors associated with these have contributed to an enormous variety of reported values for 'ultrafilterable $\mathrm{Al}^{\prime}$ ' (ranging from 6 to 95\%), but a figure of around 10\% has emerged from recent studies $[4,6]$, roughly in line with the proportion of $\mathrm{Al}$ bound to LMM compounds.

Even in animals, attempts to measure the filterability of $\mathrm{Al}$ at physiological plasma concentrations have relied on in vitro determinations using artificial membranes, since the volumes of glomerular filtrate that can be obtained by direct micropuncture collections in vivo are too small to allow measurement of such low Al concentrations. In the only study reported thus far (in rats), in vitro measurements indicated a surprisingly high figure of $60 \%$ filtration of endogenous $\mathrm{Al}$ [7], although the animals had received a considerable amount of saline and had been subjected to significant blood losses, thereby reducing plasma protein concentration and perhaps increasing the proportion of $\mathrm{Al}$ bound to LMM compounds.

\section{Pathological Concentrations}

Several studies have suggested that in patients with renal insufficiency, in whom plasma $\mathrm{Al}$ concentrations are often raised markedly, the ultrafilterable fraction of $\mathrm{Al}$ is slightly elevated [see 4], possibly owing to the raised plasma phosphate concentrations (and therefore increased LMM binding) in these patients.

Induction of high plasma concentrations in rats has shown that filtration of $\mathrm{Al}$ is greatly dependent on both its concentration and speciation. When administered intravenously as aluminium chloride or aluminium sulphate, percentage filterability (measured in vitro) fell progressively as the plasma concentration increased [7, 8], whereas when aluminium citrate was infused, filterability was unaffected by plasma $\mathrm{Al}$ concentration, remaining at the relatively high value of $\sim 80 \%$ [9]. In another study, using the same Amicon filtration system, but in which plasma $\mathrm{Al}$ was altered by addition of aluminium citrate to the drinking water, the subsequent intravenous infusion of citrate did not increase Al filterability [10]. The apparent contrast between these findings might reflect the differing protocols of the two studies. Two groups have measured $\mathrm{Al}$ filterability in vivo by collecting fluid directly from Bowman's space, made feasible by the use of Munich-Wistar rats whose kidneys have a number of surface glomeruli accessible to micropuncture. In order to allow the determination of $\mathrm{Al}$ concentrations in the small volumes of tubular fluid obtained, it was necessary to use very high doses of $\mathrm{Al}$. In one, the $\mathrm{Al}$ was administered intravenously as aluminium chloride (plasma $\mathrm{Al}$ concentration $\sim 25-120 \times$ normal); Al filterability was inversely correlated to its plasma concentration, and ranged from 2 to $8 \%$ [11], echoing the in vitro findings of Lote et al. [7]. This low filterability at high concentrations is thought to be a consequence of formation of insoluble complexes [7]. More recently, a second micropuncture study has been performed using similar plasma concentrations, but with one important difference: the $\mathrm{Al}$ was administered as aluminium citrate [12]. In this case, filterability was found to be virtually $100 \%$ at each dose, which was significantly higher than the in vitro filterability measured simultaneously. To summarise: although important quantitative differences exist between in vitro and in vivo measurements, both approaches indicate that Al filterability is concentration dependent except when complexed with citrate.

\section{Tubular Handling of Aluminium}

In order to assess the tubular handling of $\mathrm{Al}$, it is necessary to measure not only the glomerular filtration rate (GFR) and the renal clearance of $\mathrm{Al}\left(\mathrm{C}_{\mathrm{Al}}\right)$, but also its filterability. Studies in which all three variables have been determined are extremely rare. 


\section{Physiological Concentrations}

Values for endogenous $\mathrm{C}_{\mathrm{Al}}$ in healthy humans have been reported (or can be calculated from the published data) to be approximately $3 \mathrm{ml} / \mathrm{min}$ [13-15], equivalent to $\sim 2 \%$ of the GFR (assessed by creatinine clearance) [14]. Recently, accelerator mass spectrometry has been employed to study the kinetics of tracer doses of orally administered ${ }^{26} \mathrm{Al}[6]$. In 3 healthy males, $\mathrm{C}_{\mathrm{Al}}$ averaged $\sim 12 \mathrm{ml} / \mathrm{min}$, equivalent to $\sim 9 \%$ of the creatinine clearance. It is clearly impossible to arrive at a consensus figure for tubular $\mathrm{Al}$ handling from these disparate findings. Assuming that approximately $10 \%$ of plasma $\mathrm{Al}$ is filterable, fractional excretion of $\mathrm{Al}\left(\mathrm{FE}_{\mathrm{Al}}\right)$ would be between 20 and $90 \%$ of the filtered load.

In rats, Lote et al. [7] found that endogenous $\mathrm{C}_{\mathrm{Al}}$ was $\sim 8 \%$ of the simultaneously measured GFR, which accords with the findings of studies using ${ }^{26} \mathrm{Al}$ [16]. In contrast, data from another investigation in rats indicated a value for endogenous $\mathrm{C}_{\mathrm{Al}}$ of $\sim 20 \%$ of the GFR [10]. In the absence of information on the filterability of $\mathrm{Al}$, it is not possible to determine how much, if any, $\mathrm{Al}$ was reabsorbed. Only Lote et al. [7] provided this information, and in that study there was evidence for substantial $\mathrm{Al}$ reabsorption in the nephron as a whole. No attempts to localise the nephron segments responsible have been possible, because the small volumes of tubular fluid obtained by micropuncture preclude the measurement of endogenous Al. Nor have any indirect approaches, such as treatment with selective diuretics, been applied. Possible mechanisms of Al reabsorption are by no means clear: as yet, no specific transporter systems for $\mathrm{Al}$ have been identified in renal tubular membranes. In mammalian brain, there is evidence that aluminium citrate can be carried on the $\mathrm{H}^{+}$-monocarboxylate transporter [17], and isoforms of this transporter are found in some nephron segments [18]; but it is not yet known whether renal isoforms can transport aluminium citrate. It might be supposed that at least some filtered $\mathrm{Al}$ would be reabsorbed passively in the proximal tubule, down its concentration gradient following water abstraction. However, a recent micropuncture study using high plasma concentrations of $\mathrm{Al}$ has shown that no significant passive $\mathrm{Al}$ reabsorption takes place in this segment (see below) [12].

\section{Pathological Concentrations}

Although information about altered tubular handling in uraemic patients with raised plasma $\mathrm{Al}$ concentrations is patchy, there is some indication that fractional $\mathrm{Al}$ reabsorption is reduced. $\mathrm{C}_{\mathrm{Al}} / \mathrm{GFR}$ (GFR being assessed as creatinine clearance) has been reported to increase in renal failure [14] and values in renal transplant patients under- going immunosuppressive therapy are higher than those in healthy subjects $[19,20]$, but in no case was $\mathrm{Al}$ filterability measured. $\mathrm{C}_{\mathrm{Al}} / \mathrm{GFR}$ was also high $(\sim 30 \%)$ in a group of dialysis patients in whom creatinine clearance values were extremely low [21]. The ${ }^{26} \mathrm{Al}$ study of Steinhausen et al. [6] indicated a modest increase in $\mathrm{C}_{\mathrm{Al}} / \mathrm{GFR}$ in renal failure patients, whilst a corresponding study in the $5 / 6$ nephrectomy rat model [16] showed a more marked increase: $20 \%$ vs. $7 \%$ (although only 2 rats were studied).

In healthy animals, plasma $\mathrm{Al}$ concentrations have been artificially elevated by intravenous infusion; the consequences for $\mathrm{Al}$ excretion depend very much on the $\mathrm{Al}$ species used. Lote et al. [7] infused aluminium chloride and found that $\mathrm{C}_{\mathrm{Al}}$ fell as the plasma concentration increased. The same observation was made in the isolated perfused rat kidney [22]. However, this is simply a reflection of the reduced filterability of $\mathrm{Al}$ at higher plasma $\mathrm{Al}$ concentrations. Lote et al. [7] showed that when filterability (measured in vitro) was taken into account, $\mathrm{FE}_{\mathrm{Al}}$ increased markedly at the higher plasma $\mathrm{Al}$ concentrations. A similar conclusion was reached when intravenous infusions of aluminium citrate or aluminium sulphate were used: for both species of infused $\mathrm{Al}, \mathrm{FE}_{\mathrm{Al}}$ was $\sim 70 \%$ at the highest filtered loads. Al excretion was much more efficient when citrate was infused (fig. 1), which was wholly attributable to the higher filterability of $\mathrm{Al}$ in this form [8].

In a pioneering study, Burnatowska-Hledin et al. [11] infused aluminium chloride into rats and calculated $\mathrm{FE}_{\mathrm{Al}}$ by comparing the urinary excretion of $\mathrm{Al}$ with direct micropuncture measurement of ultrafiltered $\mathrm{Al}$ in glomerular filtrate. At plasma concentrations $25-120 \times$ normal, $\mathrm{FE}_{\mathrm{Al}}$ approximated $40 \%$, which increased to $>80 \%$ following volume expansion.

The first direct micropuncture assessment of segmental Al transport along the nephron has been performed recently in our laboratory. Using Munich-Wistar rats infused with three doses of aluminium citrate to achieve plasma concentrations of approximately 30,60 and $120 \times$ normal, Al deliveries to Bowman's space were compared with those at the end of the proximal convoluted tubule (PCT) and the beginning of the distal tubule, as well as in the final urine [12]. Somewhat surprisingly, at these high plasma concentrations and correspondingly high filtered loads, no evidence was found for significant net Al transport in the PCT. Owing to limitations in precision of measurement, the possibility of some $\mathrm{Al}$ reabsorption in the PCT cannot be discounted (which might be quantitatively significant at normal filtered loads), but it is clear that any such reabsorption must be subject to transport maximum limitation. In contrast to the PCT, we found that 

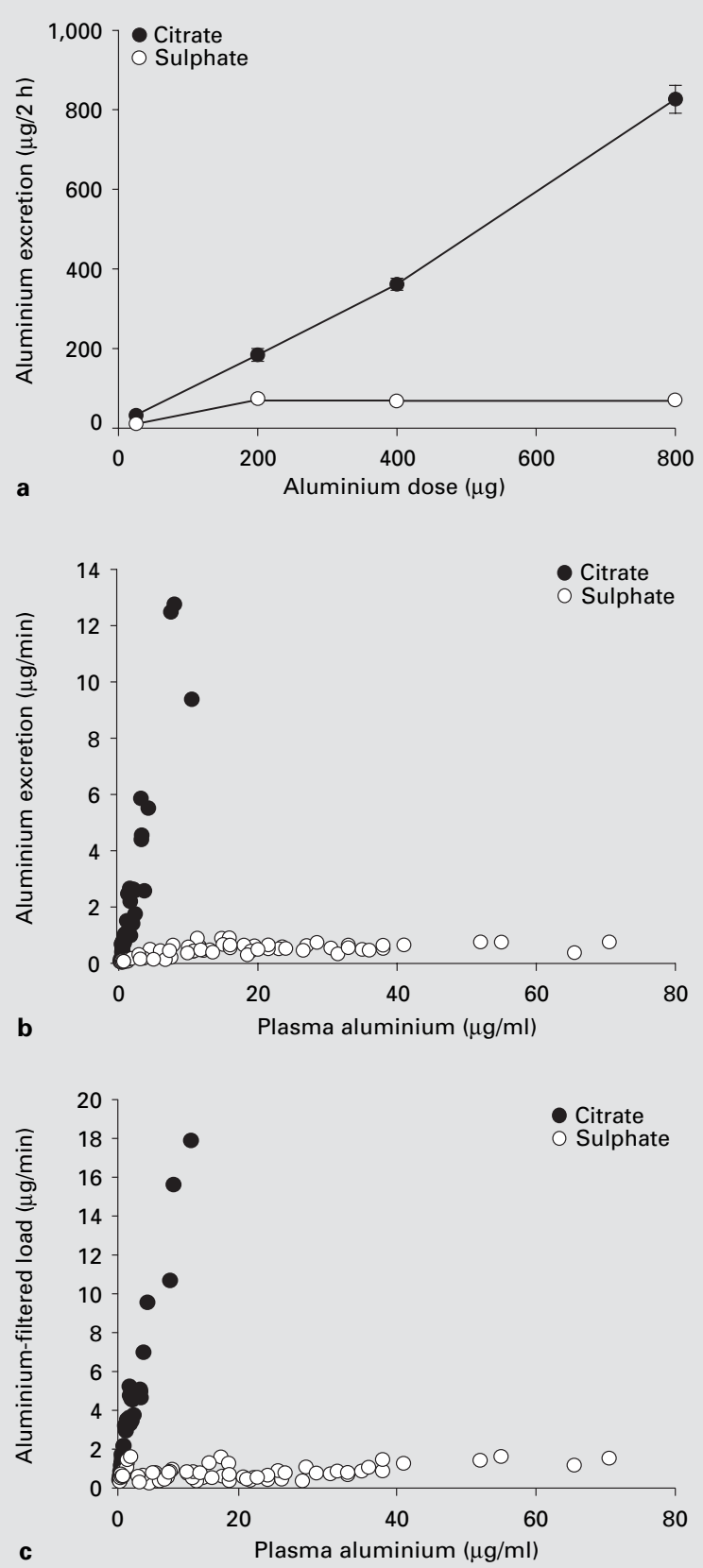

Fig. 1. a $\mathrm{Al}$ excretion in the urine of rats following intravenous administration of bolus doses of $\mathrm{Al}$ as either sulphate or citrate. Values are means \pm SEM. b Same experiment as figure 1a, but with $\mathrm{Al}$ excretion plotted against plasma $\mathrm{Al}$ concentration. Each point is a value from a single rat. c Same experiment as figure $1 \mathrm{a}$, but with filtered load of Al (calculated as GFR $\times$ plasma Al concentration $\times \mathrm{Al}$ filterability measured in vitro) plotted against plasma $\mathrm{Al}$ concentration. Each point is a value from a single rat. It is clear that the greater efficiency of $\mathrm{Al}$ excretion when administered as citrate is a consequence of the higher filtered load. Data taken from Lote et al. [8]. in all three groups a significant proportion of filtered $\mathrm{Al}$ $(20-25 \%)$ was reabsorbed in the nephron segment between the late PCT and early distal tubule: the anatomical loop of Henle (fig. 2). In the absence of evidence for a specific Al transporter in the loop, we have speculated that the likely mechanism for $\mathrm{Al}$ reabsorption at this site is paracellular transport of free $\mathrm{Al}^{3+}$ ions in the thick ascending limb (TALH), driven by the lumen-positive
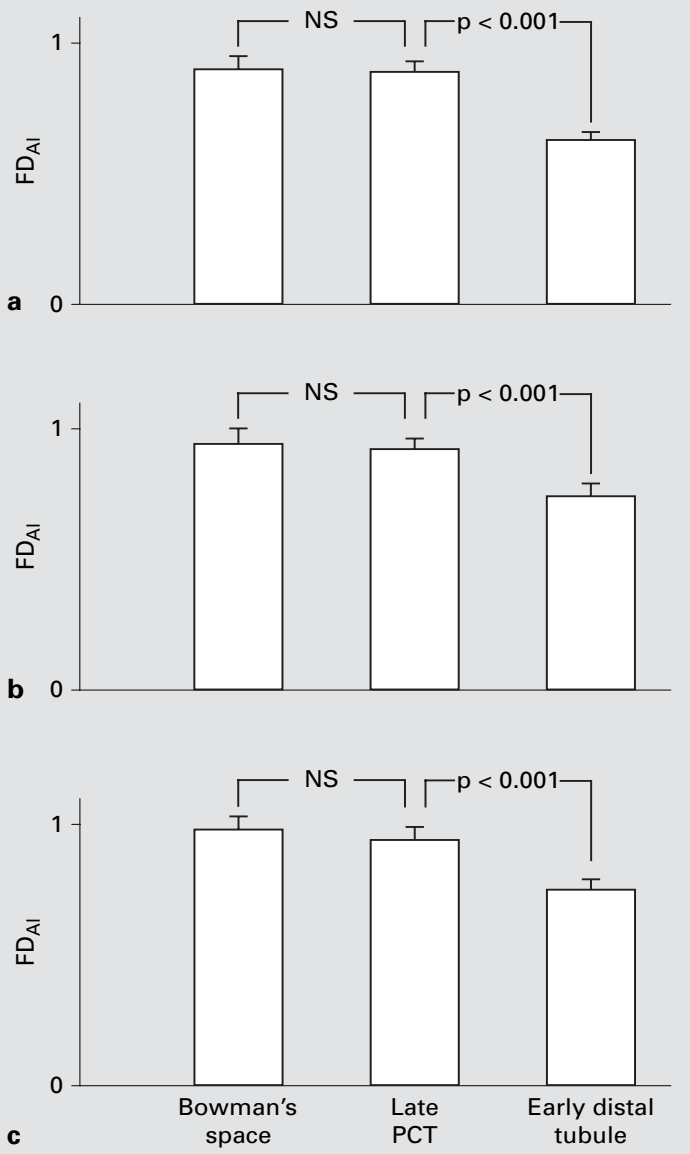

Fig. 2. Renal $\mathrm{Al}$ handling in rats infused with aluminium citrate at low dose (a), medium dose (b) or high dose (c), respectively raising plasma $\mathrm{Al}$ to concentrations 30,60 and $120 \times$ normal. Values are means $\pm \mathrm{SEM} . \mathrm{FD}_{\mathrm{Al}}=$ Fractional delivery of $\mathrm{Al}$ to each puncture site, calculated by comparison with inulin deliveries; $\mathrm{PCT}=$ proximal convoluted tubule; $\mathrm{NS}=$ not statistically significant. Note that aluminium citrate is almost freely filtered into Bowman's space and that reabsorption in the PCT is statistically insignificant. Taken, with permission, from Shirley et al. [12]. 
transepithelial potential difference of this segment. Such transport would be analogous to that of $\mathrm{Ca}^{2+}$ and $\mathrm{Mg}^{2+}$ in the TALH, and it is worth noting that the effective ionic radius of $\mathrm{Al}^{3+}$ is less than that of either $\mathrm{Ca}^{2+}$ or $\mathrm{Mg}^{2+}$.

The final observation of the micropuncture study was the absence of any evidence for net $\mathrm{Al}$ reabsorption beyond the loop of Henle at these high doses of $\mathrm{Al}$ [12]. However, at the highest dose, we did find evidence for some secretion of Al beyond the distal tubule. The mechanism of any such $\mathrm{Al}$ secretion is unknown, but our findings are consistent with earlier indirect evidence for $\mathrm{Al}$ secretion in the distal nephron of the pig [23].

In summary, although findings are not uniform between laboratories, there is some evidence that overall fractional reabsorption of $\mathrm{Al}$ within the nephron is significantly reduced at high plasma concentrations compared with that seen at normal endogenous plasma levels.

\section{Conclusion}

A considerable degree of confusion still exists with respect to the extent of $\mathrm{Al}$ filtration and reabsorption, particularly at normal plasma concentrations where mea- surements are more difficult. However, it is possible to conclude from the literature that a substantial proportion of plasma $\mathrm{Al}$ is protein bound and therefore unfilterable, and that the filtration of elevated plasma Al concentrations is very much dependent on the nature of the anion species with which the excess $\mathrm{Al}$ is complexed. When the anion is citrate, it is clear that the balance of LMM/HMM binding is tilted so that $\mathrm{Al}$ is readily filtered. It is concluded, therefore, that in cases of Al toxicity an effective means of ridding the body of $\mathrm{Al}$ would be to raise plasma citrate concentrations; the enhanced filterability, together with only modest reabsorption along the nephron, would ensure a high rate of excretion. It should be noted, however, that since dietary citrate enhances $\mathrm{Al}$ uptake from the gastrointestinal tract [1], intravenous infusion of citrate would be the preferred route of administration.

\section{Acknowledgement}

Work in the authors' laboratories was supported by the National Kidney Research Fund, the Wellcome Trust, and the Medical Research Council.

\section{References}

1 Yokel RA, McNamara PJ: Aluminium toxicokinetics: an updated minireview. Pharmacol Toxicol 2001;88:159-167.

2 Hewitt CD, Savory J, Wills MR: Aspects of aluminum toxicity. Clin Lab Med 1990;10: 403-422.

3 Alfrey AC: Aluminum metabolism. Kidney Int 1986;29(suppl 18):S8-S11.

-4 Van Landeghem GF, de Broe ME, d'Haese PC: $\mathrm{Al}$ and Si: their speciation, distribution, and toxicity. Clin Biochem 1998;31:385-397.

5 Öhman LO, Martin RB: Citrate as the main small molecule binding $\mathrm{Al}^{3+}$ in serum. Clin Chem 1994:40:598-601.

-6 Steinhausen C, Kislinger G, Winklhofer C, Beck E, Hohl C, Nolte E, Ittel TH, AlvarezBrückmann MJL: Investigation of the aluminium biokinetics in humans: a ${ }^{26} \mathrm{Al}$ tracer study. Food Chem Toxicol 2004;42:363-371.

7 Lote CJ, Wood JA, Saunders HC: Renal filtration, reabsorption and excretion of aluminium in the rat. Clin Sci 1992;82:13-18.

-8 Lote CJ, Wood JA, Thewles A, Freeman M: Renal filtration and excretion of aluminium in the rat: dose-response relationships and effects of aluminium speciation. Hum Exp Toxicol 1995; 14:494-499.

-9 Lote CJ, Saunders HC, Wood JA, Spencer AJ: Effect of citrate on plasma aluminium concentration and aluminium excretion in the rat. Clin Sci 1992;83:431-435.
10 Cochran M, Chawtur V, Phillips JW, Dilena B: Effect of citrate infusion on urinary aluminium excretion in the rat. Clin Sci 1994;86:223226.

11 Burnatowska-Hledin MA, Mayor GH, Lau K: Renal handling of aluminum in the rat: clearance and micropuncture studies. Am J Physiol 1985;249:F192-F197.

12 Shirley DG, Walter MF, Walter SJ, Thewles A, Lote CJ: Renal aluminium handling in the rat: a micropuncture assessment. Clin Sci 2004: 107:159-165.

13 Wilhelm M, Höhr D, Abel J, Ohnesorge FK: Renal aluminum excretion. Biol Trace Elem Res 1989;21:241-245.

14 Burgess E, Muruve D, Audette R: Aluminum absorption and excretion following sucralfate therapy in chronic renal insufficiency. Am J Med 1992:92:471-475.

15 Chiba J, Kusumoto M, Shirai S, Ikawa K, Sakamoto S: The influence of fluoride ingestion on urinary aluminum excretion in humans. Tohoku J Exp Med 2002;196:139_ 149.

16 Meirav O, Sutton RAL, Fink D, Middleton R, Klein J, Walker VR, Halabe A, Vetterli D, Johnson RR: Accelerator mass spectrometry: application to study of aluminum kinetics in the rat. Am J Physiol 1991;260:F466-F469.

17 Ackley DC, Yokel RA: Aluminum transport out of brain extracellular fluid is proton depen- dent and inhibited by mersalyl acid, suggesting mediation by the monocarboxylate transporter (MCT1). Toxicology 1998;127:59-67.

18 Garcia CK, Brown MS, Pathak RK, Goldstein JL: cDNA cloning of MCT2, a second monocarboxylate transporter expressed in different cells than MCT1. J Biol Chem 1995;270:18431849.

19 Davenport A, Davison AM, Newton KE, Will EJ, Giles GR, Toothill C: Urinary aluminium excretion following renal transplantation and the effect of pulse steroid therapy. Ann Clin Biochem 1990;27:25-32.

20 Grosso S, Douthat W, Garay G, de Arteaga J, Boccardo G, Fernández Martín JL, Canteros A, Cannata Andía J, Massari P: Time course and functional correlates of post-transplant aluminium elimination. Nephrol Dial Transplant 1998;13(suppl 3):98-102.

$\checkmark 21$ Altman P, Butter KC, Plowman D, de Saintonge DMC, Cunningham J, Marsh FP: Residual renal function in hemodialysis patients may protect against hyperaluminemia. Kidney Int 1987;32:710-713.

22 Höhr D, Abel J, Wilhelm M: Renal clearance of aluminium: studies in the isolated perfused rat kidney. Toxicol Lett 1989;45:165-174.

23 Monteagudo FSE, Isaacson LC, Wilson G, Hickman R, Folb PI: Aluminium excretion by the distal tubule of the pig kidney. Nephron 1988;49:245-250. 